\title{
Should Clinical Education be Integrated into the Postgraduate Radiography Training Programmes?
}

\author{
Bwanga, $O$.
}

\begin{abstract}
Clinical education is an essential component of postgraduate radiography training programmes. Most of the teaching and learning happens in the radiology department. Advanced radiographer practitioners and consultant radiographers act as clinical educators of radiography students and radiographers undertaking on-the-job training and postgraduate studies. However, many teach without receiving formal training in clinical education, even though it is widely recognised as a way of improving the standards of radiography education. There is a need to integrate clinical education into postgraduate training programmes to impart radiographers with appropriate knowledge and skills in facilitation of learning.
\end{abstract}

Keywords: Clinical education, Postgraduate, Radiography

\section{Introduction}

Radiography plays an important role in the diagnosis and management of diseases and injuries in medicine. In the medical context, radiography is an art and science that uses radiation to allow for the visualisation of tissues, organs, and vessels that comprise the human body. Generally, undergraduate training focuses on general radiography and a basic understanding of different imaging modalities such as computed tomography (CT), magnetic resonance imaging (MRI), nuclear medicine (NM), mammography, and ultrasonography (US). Some radiographers undertake postgraduate specialised training in medical imaging after their undergraduate qualification and gaining some experience. At this level, radiographers take on advanced practice and consultancy roles in their respective specialities. One of their roles is to provide education and training to students and other radiographers undertaking on-the-job training or formal courses (College of Radiographers, 2017). In other words, they automatically become clinical educators.

The clinical educational process has three

Midland Regional Hospital at Tullamore, Ireland

Corresponding Author: Dr Osward Bwanga (PhD), Midland Regional Hospital at Tullamore, Ireland.

Email: o.bwanga@yahoo.com

DOI: http://doi.org/10.4038/seajme.v14i2.250 elements: the curriculum, the student, and the clinical educator (Harden \& Laidlaw, 2017). In radiography, global literature shows that more attention has been paid to the curriculum and students than to the clinical educators. More emphasis is placed on learning outcomes, teaching and learning methods, assessment procedures and strategies on how students and postgraduate trainees can learn more effectively than is placed on training clinical educators in clinical teaching (Cunningham et al., 2015; England et al., 2017). It should be stressed that clinical educators are key players in the implementation of the curriculum; teaching students and assessing their progress (Steinert, 2014; Harden \& Laidlaw, 2017). This means that the success or failure of the radiography clinical education programme largely depends on clinical educators. The question is:

"How can radiographers pursuing postgraduate radiography studies be supported to acquire the appropriate knowledge, skills, attitudes, and competence needed for clinical education"?

\section{Role of Designated Radiographers in Education and Training}

Clinical educators play an important role in radiography education programmes. Generally, undergraduate radiography students are supervised by clinical educators who hold an undergraduate qualification or those with 
additional specialised qualifications. Their main roles include organising and managing training resources, clinical teaching and learning, role modelling, giving feedback to students, conducting the clinical and performance-based assessments, and supporting students with social problems and learning difficulties (Cunningham et al., 2015; England et al., 2017). However, clinical education is not integrated into the radiography curriculum to support them in performing this role effectively and efficiently and few clinical educators receive clinical supervisory training before taking up this role. For example, a survey conducted in European countries on clinical education in radiography by English and others (2017), found less than half $(44.7 \%)$ of academic institutions allow only trained clinical educators to supervise students and the majority $(63.2 \%)$ do not provide clinical supervision training. This finding may be similar or worse in developing countries.

As stated earlier radiographers with specialised qualifications are responsible for providing education and training in their respective areas of medical imaging (College of Radiographers, 2017). However, many teach without receiving formal training in clinical education (Cunningham et al., 2015; England et al., 2017), even though the training of educators is widely recognised as a way of improving the effectiveness and efficiency of learning and of enhancing students' experiences (Steinert, 2014; Harden \& Laidlaw, 2017). To improve education standards in radiography, there is a need to find a solution to this challenge.

\section{Problem with Radiography Education System}

In radiography, the knowledge, skills, attitudes, and competence required of a clinical educator have been underestimated. It is often assumed that radiographers with postgraduate imaging specialisations are good clinical educators and can teach their colleagues undertaking on-thejob training or postgraduate studies. Sadly, this is not true, resulting in shortcomings and bad clinical education practices. In radiography clinical education, the identified problems include a lack of clear clinical teaching and learning outcomes, a lack of constructive feedback on students' performances, and poor assessments (Cunningham et al., 2015; England et al., 2017). These problems may be due to a lack of clinical education training amongst clinical educators.
The other challenge is the absence of relevant subjects in postgraduate education and training programmes. In recent years, there has been a move from the traditional curriculum where the emphasis is on acquiring knowledge and skills and passing an examination to an authentic curriculum (Harden \& Laidlaw, 2017). The authentic curriculum emphasises the incorporation of subjects that are relevant to the practice of radiography. In the context of this paper, this means the integration of clinical education in postgraduate education and training programmes. This strategy will allow clinical educators to be trained in educational principles whilst pursuing their postgraduate studies and prepare them for their role in education and training. Harden and Laidlaw (2017) point out that good clinical teaching, just like any other field of professional endeavour, is best delivered when there is an understanding of the underlying process. This means that clinical education should not be conducted by the trial and error method of teaching and learning.

\section{Conclusion}

The main challenge of clinical education in radiography is a lack of teacher training amongst designated radiographers involved in the facilitation of practice-based learning. To overcome this challenge, it is highly recommended that postgraduate educational programmes should integrate clinical education to make the curriculum relevant to radiography trainees. This strategy would enable radiographers pursuing postgraduate studies to simultaneously acquire the medical imaging specialisation qualification and training in clinical education. This would assist them in performing the education and training role upon completion of their studies.

\section{References}

College of Radiographers (2017). Consultant radiographer-guidance for the support of new and established roles. London: The College of Radiographers.

Cunningham, J., Wright, C., \& Baird, M. (2015). Managing clinical education through understanding key principles. Radiologic Technology, 86 (3): 257-273.

England, A., Gemeren, S.G., Henner, A,. Kukkes, T., Pronk-Larive, D., Rainford, L. \& McNulty, J.P. (2017). Clinical radiography education across Europe. Radiography, 23 (1): 7-15. 
Harden, R.M. \& Laidlaw, J.M. (2017). Essential skills for a medical teacher-An introduction to teaching and learning in medicine. $2^{\text {nd }}$ edition. London: Elsevier.
Steinert, Y. (2014). Developing medical educators: a journey not a destination. In: Swanwick, T., Ed. Understanding medical education: evidence, theory and practice ( $2^{\text {nd }}$ Edition). Oxford: John Wiley \& Sons Ltd, Pp 455-469. 